\title{
INFORMAÇÃO E IDEOLOGIA: DIÁLOGOS FILOSÓFICOS NO ÂMBITO DO PROSELITISMO INFORMACIONAL
}

\author{
Jonathas Luiz Carvalho Silva \\ Doutor em Ciência da Informação pela Universidade Federal da Bahia (UFBA) \\ Professor do Curso de Biblioteconomia da Universidade Federal do Cariri (UFCA) \\ E-mail: jonathascarvalhos@yahoo.com.br
}

\begin{abstract}
Resumo
Aborda relações entre informação e ideologia no âmbito do conceito de proselitismo informacional. A seguinte pergunta é formulada como ponto partida: como se constitui conceitualmente o proselitismo informacional considerando suas características e perspectivas de ação? O objetivo do estudo é discutir sobre as relações entre os conceitos de informação e ideologia nos meandros da construção filosófica em Marx, Mannheim, Thompson e Bakhtin, com o intuito de compreender a fundamentação analítico-conceitual do proselitismo informacional. A metodologia foi construída no contexto da pesquisa bibliográfica permitindo ao pesquisador a cobertura de uma gama de fenômenos possibilitando a elaboração de um processo reflexivo baseado em múltiplos diálogos com a literatura científica nacional e internacional em Ciência da Informação, Filosofia e áreas afins de diferentes períodos históricos. Conclui-se que o proselitismo informacional se configura como prática que deturpa o significado humano e verídico da informação pautada em práticas positivistas, utilitaristas e antiéticas.
\end{abstract}

Palavras-chave: Informação. Ideologia. Proselitismo informacional.

\section{INFORMATION AND IDEOLOGY: PHILOSOPHICAL DIALOGS IN THE SCOPE OF INF ORMATIONAL PROSELYTISM}

\begin{abstract}
Discusses relations between information and ideology under the concept of information proselytism. The next question is formulated as a starting point: how is being conceptually constituted the informational proselytism considering its features and action prospects? The objective is to discuss the relationship between the concepts of information and ideology in the intricacies in Marx, Mannheim, Thompson and Bakhtin'a philosophical construction, in order to understand the conceptual basis of the analytical-informational proselytism. The methodology was built in the context of literature allowing the researcher to cover a range of phenomena, enabling the development of a reflective process based on multiple dialogues with national and international scientific literature in Information Science, Philosophy, and related areas of different historical periods. It is concluded that the informational proselytism is configured as a practice that distorts the true meaning of human and information guided by positivist, utilitarian, and unethical practices.
\end{abstract}

Key-words: Information. Ideology. Informational proselytism. 


\section{Introdução}

Toda produção informacional é ideológica. Esta afirmação norteará as reflexões deste estudo. Juntamente e/ou de forma subjacente à linguagem, a ideologia aparece como elemento de construção de sentidos e apropriação de conteúdos no sentido de manipular as formas de pensamento, a formação da consciência e as atividades linguísticas (discursivas e pragmáticas).

O presente estudo se constitui nas relações entre informação e ideologia a partir de alguns diálogos conceituais sobre ideologia com Marx, Mannheim, Thompson e Bakhtin, mostrando aplicações de suas conceituações às concepções de informação. Os conceitos dos autores e suas aplicações no espectro da informação sustentam o que é denominado de proselitismo informacional.

Tomando por base a configuração relacional contemporânea entre informação e ideologia formula-se a seguinte pergunta como ponto partida: como se constitui conceitualmente o proselitismo informacional, considerando suas características e perspectivas de ação?

O objetivo do estudo é discutir as relações entre os conceitos de informação e ideologia nos meandros da construção filosófica em Marx, Mannheim, Thompson e Bakhtin, com o intuito de compreender a fundamentação analítico-conceitual do proselitismo informacional.

A metodologia foi construída no contexto da pesquisa bibliográfica, permitindo ao pesquisador a cobertura de uma gama de fenômenos e possibilitando a elaboração de um processo reflexivo baseado em múltiplos diálogos com a literatura científica nacional e internacional em Ciência da Informação, Filosofia e áreas afins de diferentes períodos históricos.

\section{Percepções preliminares sobre ideologia aplicadas à informação}

A despeito das percepções tipológicas da "ideologia neutra e da ideologia crítica", optamos pela segunda por considerar que o ethos semântico da ideologia reside nos processos de conflito e dominação entre os sujeitos da informação. É pertinente discordar da ideia de neutralidade ideológica, mesmo quando esta implica apenas na elaboração estratégica de discursos, ideias e ações, pois toda ideologia carrega em si (em seus vieses discursivos e 
pragmáticos) cargas da manipulação ou tendências (individuais ou coletivas; singulares ou plurais).

Para tanto, o estudo se apropria das questões de ideologia levantadas por Karl Marx, Karl Mannheim, John Thompson e Mikhail Bakhtin que concernem a fundamentação crítica da semântica ideológica e das conduções conflituosas e possivelmente dominatórias entre os sujeitos da informação, atestando o caráter eminentemente filosófico, sociológico e a institucionalização contemporânea do conceito de ideologia. O diálogo com os respectivos autores nos permite perceber, de maneira plural, como a informação se insere em uma perspectiva eminentemente ideológica.

Marx (2001, p. 3), ao questionar o conceito de ideologia afirma que "os homens sempre tiveram ideias falsas a respeito de si mesmos, daquilo que são ou deveriam ser" postulando a concepção de ideologia como procedimento de representação deturpada da realidade. De forma mais clara, o conceito de ideologia em Marx é atribuído por Lowy (1992, p. 12) da seguinte forma:

Em A Ideologia Alemã, o conceito de ideologia aparece como equivalente à ilusão, falsa consciência, concepção idealística na qual a realidade é invertida e as idéias aparecem como motor da vida real. Mais tarde Marx amplia o conceito e fala das formas ideológicas através das quais os indivíduos tomam consciência da vida real, ou melhor, a sociedade toma consciência da vida real. Ele as enumera sendo religião, a filosofia, a moral o direito, as doutrinas políticas, etc.

De quais formas o conceito de ideologia de Marx (e extensivamente de várias apropriações marxistas) incide sobre as questões da informação? Em primeiro lugar é preciso reconhecer que o conceito marxiano de ideologia está impregnado da concepção de uma falsa consciência, o que, por conseguinte, promoveria a concepção de uma falsa informação ou uma informação deformada, comumente no sentido de satisfazer um grupo minoritário de pessoas em detrimento de uma maioria ou, de forma mais clara, no sentido de constituir uma informação que deixe latente a dominação de um grupo minoritário sobre os demais. Neste caso, a ideologia funciona como um pano de fundo para ludibriar os sujeitos de que aquela informação pode ser única ou a mais adequada para determinada questão.

Pode-se destacar que o conceito de ideologia em Marx pode ser identificado à percepção de informação a partir de outros contextos, tais como:

a) Leva em consideração o contexto de quem domina os meios e instrumentos de comunicação e linguagens (verbais ou não-verbais) para determinar o que é verdadeiro ou 
falso; verdade ou mentira; adequado ou inadequado; errado ou certo, conforme suas conveniências, denotando uma visão positivista de manipulação dos fatos e de uma percepção unilateral da informação, ou seja, a informação sempre tem dois lados e não é possível enxergar de forma mais ampla;

b) Possui a intencionalidade prévia de estabelecer uma interlocução unilateral, sem dar direito de resposta ou interação para os outros sujeitos da informação;

c) Busca conquistar os sujeitos da informação com falsas promessas e ilusões de que a realidade, a informação mais apropriada, é a determinada pelo sujeito autor ou sujeito mediador;

d) Inverte a concepção de que a informação não deve ser apropriada a partir da realidade objetiva, mas que pode ser simplesmente intuitiva ou pré-determinada por alguém que tenha embasamento para emitir a informação que deseja (a informação pode ser um simples fruto da consciência, deturpando a formação de uma consciência pautada nas interações multilaterais e baseada no respeito às diferenças entre os sujeitos);

e) A ideologia cria condições para aceitação ou resistência sobre como a informação deve ser construída, compreendida e apropriada pelos sujeitos.

Em síntese, a formação de ideias e ideologias falsas ou deturpadas (no sentido de favorecer interesses próprios em detrimento de interesses majoritários) incidem diretamente sobre a construção de informações falsas ou deturpadas que não condizem de maneira efetiva com a realidade social.

Em Karl Mannheim a ideologia possui uma tonalidade mais geral e tipologizada, principalmente pela sua focalização nos estudos sobre a sociologia do conhecimento. Mannheim (1976) que fala sobre duas concepções relativas ao termo: a particular e a total. A concepção particular de ideologia é implicada quando o termo denota certo ceticismo das ideias e representações apresentadas por aqueles indivíduos ou grupos sociais que se opõem às ideias de outros indivíduos e grupos. O autor fala que estas ideias são encaradas como disfarces mais ou menos conscientes da real natureza de uma situação, cujo reconhecimento não estaria de acordo com seus interesses. Essas distorções variam numa escala que vai desde mentiras conscientes até os disfarces semiconscientes e dissimulados. Esta concepção de ideologia, que veio gradativamente sendo diferenciada da noção de mentira, encontrada no senso comum, é particular em vários sentidos. Sua particularidade se torna evidente quando é contrastada com a concepção total, mais inclusiva, da ideologia. A concepção total de ideologia inclui o entendimento sobre uma época ou de um grupo histórico-social concreto, 
por exemplo, de uma classe, ocasião em que se evidenciam as características e a composição da estrutura total da mente desta época ou deste grupo.

A tipologia concebida por Mannheim nos leva a compreender que ideologia e informação estão intrinsecamente concatenadas, considerando que a ideologia é um fenômeno abstrato de apreensão da realidade que tem por finalidade manipular e convencer os sujeitos de que a percepção de um sujeito (ou grupo de institucionais de sujeitos) é a mais adequada.

Além disso, é preciso reconhecer, em primeiro lugar, que a produção da informação envolve cargas ideológicas promovidas pelos sujeitos da informação. Como afirma Mészáros (2004, p. 57) “[...] em nossas sociedades tudo está ‘impregnado de ideologia’ quer a percebamos, quer não.” Ora, se nossas sociedades estão impregnadas de ideologia, seja ela particular ou total, significa que toda informação está atrelada a fenômenos ideológicos que podem ser reconhecidos, em segundo lugar, a partir de três grandes contextos informacionais: particular, situacional e geral.

O particular é referente ao contexto em que a informação é produzida por um sujeito a partir do contato direito ou indireto com documentos/artefatos ou meios de comunicação, mas sem a constituição de uma interação mútua entre os sujeitos. É o caso, por exemplo, da informação produzida por sujeitos que assistem a programação em diferentes mídias (TV, rádio, conteúdos da web, jornal impresso ou digital, etc.) absorvendo cargas ideológicas das programações, mas comumente sem haver uma interação direta. Este tipo de informação está ligado à ideologia no contexto marxiano de que há uma determinação de um sujeito que emite um conteúdo conforme suas conveniências, mas não oportuniza (por falta de vontade ou de condições físicas e institucionais) requisitos para exposição dos sujeitos da informação que participam daquele diálogo.

Neste caso, a ideologia do sujeito/autor da informação impregna todo o processo de construção da informação possibilitando a outros sujeitos aceitarem essa carga ideológica e produzirem informação de acordo com as influências do sujeito/autor, ou desenvolver atos de resistência ao considerarem que aquela informação é tendenciosa e não se adéqua às suas necessidades. Esta informação é particular porque sustenta as concepções dos indivíduos em caráter mais isolado.

A informação ainda pode ser particular quando trata de elementos bióticos como, por exemplo, DNA ou o sentimento de alguns sintomas orgânicos (LOGAN, 2012) em que os sujeitos produzem informação a partir de dados que podem ser registrados formalmente (a partir de documentos verbais ou não-verbais) ou simplesmente a partir de intuições do sujeito produtor da informação. 
Já neste caso a informação não é transmitida por um sujeito, mas envolve a carga ideológica do próprio sujeito produtor da informação (sujeito/usuário) que precisa lidar com aspectos considerados não-humanos da realidade para produzir informação com a finalidade de esclarecer a si mesmo e satisfazer necessidades e desejos individuais.

Já o contexto situacional é uma consequência do contexto anterior, pois incide sobre a capacidade dos sujeitos se reunirem e, a partir das informações produzidas em âmbito individual, colocá-las em debates e possíveis conflitos a fim de primar por uma produção coletiva e/ou institucional da informação. O contexto situacional é uma forma de confrontar ideologias e estabelecer critérios de avaliação para produção da informação, de modo que o diálogo direto entre os sujeitos torna a informação mais lapidada e passível de exposições, análises, críticas, descobertas e retificações em caráter coletivo.

O contexto geral, por sua vez, é o caráter mais amplo da informação, já que leva em consideração os diversos contextos históricos em que os sujeitos estão situados. A informação, neste momento, não se situa apenas na base de uma ideologia, mas se constitui a partir de um "hibridismo ideológico" ${ }^{1}$ que formula a identidade informacional do sujeito, ou seja: quais tipos de informação o sujeito comumente procura construir; de quais formas procura construir informação; a partir de quais instrumentos procura se informar; dialogando com quais sujeitos (humanos e não-humanos) procura se informar; quais pontos seleciona para produzir informação, conforme as conveniências de cada contexto; qual a finalidade da produção informacional e se os sujeitos aceitam modificar essas finalidades, de acordo com as mudanças de pensamento promovidas através dos processos que se utiliza para produzir informação.

Contudo, o contexto geral da informação, ao ser diretamente influenciado pela ideologia, recebe influências diretas dos contextos particular e situacional, podendo se concretizar a partir de um efetivo reducionismo, tornando a história dos sujeitos mera seleção conveniente de fatos, prejudicando os procedimentos de produção da informação. Isso significa que a ideologia, embora seja impregnada no sujeito, possui intensidades de impregnação e essas intensidades definem procedimentos de como o sujeito deve produzir a informação. O nível mais intenso da ideologia no sujeito que influencia na produção da informação ocorre quando “a ideologia fabrica uma história imaginária (aquela que reduz o

\footnotetext{
${ }^{1} \mathrm{O}$ hibridismo ideológico se configura em um conjunto de ideologias dos sujeitos da informação nos mais diversos devires (religiosos, profissionais, pessoais, familiares, relacionais, etc.) que influenciam direta ou indiretamente nos procedimentos de construção da informação dos sujeitos.
} 
passado e o futuro às coordenadas do presente), na medida em que atribui o movimento da história a agentes ou sujeitos que não podem realizá-lo.” (CHAUÍ, 1988, p. 120).

O contexto geral da informação (baseado nos processos históricos dos sujeitos) é diretamente influenciado pela ideologia quando o sujeito aceita de forma passiva as ideologias determinadas por outros sujeitos (individuais ou institucionais) e/ou quando constrói suas informações apenas baseadas naquilo que foi determinado por outrem.

Em outras palavras, a informação geral é reducionista quando os sujeitos possuem finalidades rígidas de compreensão e apropriação que dificilmente são modificadas a partir de interações, diálogos, exposições e novas descobertas, pois a ideologia impregnada nos sujeitos permite que estes só aceitem aquilo que lhes convém.

O conceito de ideologia em Thompson, que faz uma criteriosa revisão de pensadores como Destutt de Tracy (considerado um dos vanguardistas do conceito de ideologia), Marx, Lenin, Lukács, Mannheim, entre outros, tem seu ethos semântico pautado na ideologia a serviço do poder. De forma mais categórica, Thompson (1998, p. 76) afirma que "estudar a ideologia é estudar as maneiras como o sentido serve para estabelecer e sustentar relações de dominação.”

A ideologia em Thompson seria uma configuração prévia de sentidos indiciada por determinados sujeitos (ou grupo de sujeitos). Se a ideologia prima pela determinação de sentidos para dominação fica evidente que a informação a ser produzida não aceita resistências, contradições e uma identidade de projeto contrária aos interesses de quem pretende dominar. A informação, quando ligada a uma ideologia profusora da dominação, tem no discurso sua grande articulação lógico-ontológica e linguística.

O discurso percebido na "linguagem como forma de prática social” (FAIRCLOUGH, 2001) é um dos principais elementos de dominação ideológico-informacional. O discurso considerado pronto e acabado é o mote de alguns sujeitos para evitar questionamentos de outros sujeitos, deturpar e estabelecer o passado como imutável, relegar o futuro a um plano inferior e indicar o presente como fator único de análise.

A velha máxima “viva um dia de cada vez” é uma forma ideológica de compreender a imutabilidade do passado, relegar o futuro a segundo plano e conceber o presente como temporalidade discursiva suficientemente capaz de produzir a informação que os sujeitos necessitam. A função ideológica significaria esquecer os processos históricos e centrar-se plenamente nas certezas daqueles dominam propagando este discurso de forma massificada através dos meios de comunicação de massa. 
A ideologia, em Thompson, seria uma forma de não produzir informação autonomamente, mas que um grupo de sujeitos produza informação com base em suas ideologias, forçando uma aceitação discursivo-social por outros sujeitos, inibindo procedimentos de resistência e contradiscurso e, por conseguinte, atestando que a informação é um fenômeno pré-determinado e que não necessita de um olhar mais cauto e dialogicamente discursivo.

A grande diferença da ideologia de Thompson é que retira a percepção marxiana de ilusão. A ideologia é um fenômeno de consciência real, mas deturpada da realidade, principalmente quando a ideologia se utiliza dos instrumentos de dominação, tais como: legitimação, a dissimulação, a unificação, a fragmentação e a reificação. (THOMPSON, 1998).

Concordamos com Thompson no sentido de que se a ideologia é ilusória, a informação provavelmente também seria ilusória, mas, assim como a ideologia, a informação não é ilusória, mas uma construção, apreensão e apropriação simbólica de sentidos embasada pela tendenciosidade e unicontextualidade discursiva (prática sócio-linguística).

Ao contrário, os critérios ideológicos de dominação propostos por Thompson deliberam mais o entendimento acerca da determinação da contra-informação que também é considerada como informação, mas de forma dissimulada, fragmentada e reificada que primam pela legitimação e unificação do poder informacional do sujeito que arbitra seus interesses.

A concepção de ideologia como fenômeno de aplicação linguística é notável em Bakhtin (2002, p. 95) quando afirma:

Na realidade não são palavras o que pronunciamos ou escutamos, mas verdades ou mentiras, coisas boas ou coisas más, importantes ou triviais, agradáveis ou desagradáveis, etc. A palavra está sempre carregada de um conteúdo, ou de um sentido ideológico ou vivencial. É assim que compreendemos as palavras e somente reagimos àquelas que despertam em nós ressonâncias ideológicas ou concernentes à vida.

Mais uma vez estamos lidando com a percepção conceitual de discurso que move as atribuições da linguagem e delineia o valor ideológico das palavras e das ações dos sujeitos. O discurso, por um lado, desperta o teor pragmático da linguagem, representa o valor ideológico das palavras produzindo sentidos/significados e, por fim, engendra apreensões e apropriações da informação.

A questão fundamental é que toda e qualquer carga discursiva é eivada de um desiderato ideológico e linguístico que busca expressar fenômenos que deliberam um juízo 
informativo baseado naquilo que é pregado pela ideologia e representado pela linguagem discursiva.

Logo, se um sujeito tem a perspectiva ideológica de dominar expressará essa dominação pelo discurso e pelas ações, assim como manifestará que a única informação prestimosa será aquela que transmite efeito de dominação. E, neste caso, a informação é eminentemente transmissiva porque se baseia pela linearidade do sujeito/autor para o sujeito/usuário sem perceber as diversas manifestações comportamentais, interacionais e interpretacionais dos sujeitos.

Destarte a relação entre ideologia, linguagem (discurso) e informação pode ser elucidada pela seguinte equação:

IDEOLOGIA (MEIO DE CONDUTA) + LINGUAGEM (INSTRUMENTO DISCURSIVO) + DISPOSITIVOS (POLÍTICOS, CULTURAIS, INTELECTUAIS E MIDIÁTICOS) = INFORMAÇÃO (PRODUZIDA CONSIDERANDO NECESSIDADES INDIVIDUAIS E/OU GRUPAIS)

Considerando a ideologia um meio tendencioso para produção da informação, mas ao mesmo tempo percebendo-a como poder que “[...] afeta tanto os que negam a sua existência quanto os que reconhecem abertamente os interesses e os valores intrínsecos às várias ideologias” (MÉSZÁROS, 2004, p.64) é preciso ressaltar que os sujeitos da informação não devem obnubilar suas ideologias, mas saber lidar com elas a partir de um olhar mais cauto para o outro primando por um olhar mais interacionista e recíproco com o outro. Essa ação implicaria na percepção de que a ideologia não deve ser mais forte do que o respeito ao outro na construção da informação, mas vista como meio de interação e não de dominação.

O quadro que segue faz uma síntese sobre as relações entre ideologia e informação a partir dos quatro pensadores discutidos:

Quadro 1 - Relações entre ideologia e informação

\begin{tabular}{|l|l|l|}
\hline Pensadores & Conceitos de ideologia & $\begin{array}{l}\text { Aplicação do conceito de ideologia à } \\
\text { concepção de informação }\end{array}$ \\
\hline Marx & $\begin{array}{l}\text { Ilusão, falsa consciência, } \\
\text { concepção idealística na qual a } \\
\text { realidade é invertida e as ideias } \\
\text { aparecem como motor da vida } \\
\text { real. Formas ideológicas através } \\
\text { das quais a sociedade toma } \\
\text { consciência da vida real. }\end{array}$ & $\begin{array}{l}\text { - Dominação dos instrumentos de comunicação } \\
\text { para produção da informação; } \\
\text { - Interlocução unilateral; }\end{array}$ \\
& $\begin{array}{l}\text { - A realidade informacional mais apropriada é a } \\
\text { determinada pelo sujeito autor ou sujeito } \\
\text { mediador; } \\
\text { - A informação não deve ser apropriada a partir } \\
\text { da realidade objetiva; }\end{array}$ \\
\hline
\end{tabular}




\begin{tabular}{|c|c|c|}
\hline & & $\begin{array}{l}\text { - A ideologia cria condições para aceitação ou } \\
\text { resistência sobre como a informação deve ser } \\
\text { construída, compreendida e apropriada pelos } \\
\text { sujeitos. }\end{array}$ \\
\hline Mannheim & $\begin{array}{l}\text { Duas concepções de ideologia: a } \\
\text { particular (implicada quando o } \\
\text { termo denota certo ceticismo das } \\
\text { ideias e representações } \\
\text { apresentadas por aqueles } \\
\text { indivíduos ou grupos sociais que } \\
\text { se opõem as ideias de outros } \\
\text { indivíduos e grupos) e a total } \\
\text { (inclui o entendimento sobre uma } \\
\text { época ou de um grupo histórico- } \\
\text { social concreto). }\end{array}$ & $\begin{array}{l}\text { Contexto particular - a informação é produzida } \\
\text { por um sujeito a partir do contato direito ou } \\
\text { indireto com documentos/artefatos ou meios de } \\
\text { comunicação, mas sem a interação mútua entre } \\
\text { os sujeitos; } \\
\text { Contexto situacional - confronta ideologias e } \\
\text { estabelece critérios de avaliação para produção } \\
\text { da informação; } \\
\text { Contexto geral - diversos contextos históricos } \\
\text { em que os sujeitos estão situados ("hibridismo } \\
\text { ideológico"). }\end{array}$ \\
\hline Thompson & $\begin{array}{l}\text { A ideologia estuda as maneiras } \\
\text { como o sentido serve para } \\
\text { estabelecer e sustentar relações de } \\
\text { dominação. }\end{array}$ & $\begin{array}{l}\text { - Um grupo de sujeitos produz informação com } \\
\text { base em suas ideologias e não autonomamente; } \\
\text { - A informação é uma construção, apreensão e } \\
\text { apropriação simbólica de sentidos embasada pela } \\
\text { tendenciosidade e unicontextualidade discursiva; } \\
\text { - determinação da contra-informação que é } \\
\text { dissimulada, fragmentada e reificada e prima } \\
\text { pela legitimação e unificação do poder } \\
\text { informacional do sujeito que arbitra seus } \\
\text { interesses. }\end{array}$ \\
\hline Bakhtin & $\begin{array}{l}\text { Na realidade não são palavras o } \\
\text { que pronunciamos ou escutamos, } \\
\text { mas verdades ou mentiras, coisas } \\
\text { boas ou coisas más, importantes } \\
\text { ou triviais, agradáveis ou } \\
\text { desagradáveis, etc. A palavra está } \\
\text { sempre carregada de um } \\
\text { conteúdo, ou de um sentido } \\
\text { ideológico ou vivencial. }\end{array}$ & $\begin{array}{l}\text { As palavras ou discursos estão potencialmente } \\
\text { carregados de informação e possuem uma } \\
\text { contextualização com determinada realidade. A } \\
\text { informação está ligada a palavra como expressão } \\
\text { ideológica dos valores da vida humana. }\end{array}$ \\
\hline
\end{tabular}

Fonte: elaborado pelo autor

A informação é comumente construída por desideratos ideológicos representados por construções linguístico-discursivas. Isso significa que a informação é delineada pela concepção de poder, pois a ideologia dominante determina os meandros da informação em qualquer processo de correlação de forças ou interações. Quando a construção/produção da informação tem na ideologia seu principal fundamento, especialmente a ideologia da dominação, a lógica é a consecução da contrainformação e da concentração de poder informacional.

\section{A informação como ideologia: a formação do proselitismo informacional}

Evidenciamos que as breves reflexões filosóficas e sociológicas sobre ideologia aplicadas ao contexto da informação (passando pelas relações discursivas e linguísticas), em 
especial, aquelas promovidas por Marx, Mannheim, Thompson e Bakhtin (além do apoio que reconhecemos em Mészáros) contribuem para formação do proselitismo informacional.

Definimos o proselitismo informacional como a tentativa de um sujeito ou grupos de sujeitos institucionais, por um lado, de convencer outros sujeitos de que aquela informação é verídica ou adequada e, por outro lado, de impor arbitrária e linearmente suas informações sobre outros sujeitos da informação, de modo que aceitem e pratiquem aquela informação deliberada. Em ambos os casos, a informação é vista como fenômeno pré-determinado situado nas condições elaboradas pelo sujeito/autor e/ou sujeito/mediador e soam como fundamentos de uma dominação informacional. O proselitismo informacional pode ocorrer nas mais diversas esferas que vão desde as simples relações cotidianas entre os sujeitos, passando por questões profissionais, institucionais e culminando em questões de cunho político, cultural e religioso. O proselitismo informacional é, de fato, fruto da intolerância de um sujeito da informação sobre outrem que se fundamenta nas satisfações individuais ou institucionais e em finalidades previamente estabelecidas.

Eagleton (1997, p. 15-16) concebeu uma síntese apontando definições diversas de ideologia. Entre aqueles que estão relacionados diretamente ao proselitismo informacional destacamos os seguintes:

Um corpo de idéias característico de um determinado grupo ou classe social; Idéias que ajudam a legitimar um poder político dominante; Idéias falsas que ajudam a legitimar um poder político dominante; Comunicação sistematicamente distorcida; ${ }^{2}$

Diante dos conceitos apresentados consideramos que o proselitismo informacional está associado a todos de forma diferenciada e particularizada, pois todos os conceitos de alguma forma desempenham uma atividade ideológica de convencimento, imposição ou de uma determinação informacional da consciência dos sujeitos.

Quanto ao primeiro conceito, é o traço caracterizador da ideologia sobre a informação. Os processos de produção da informação estão compreendidos a partir da inserção do sujeito em um ou mais grupos de identificação, visando empreender tramitações ideológicas que ajudam a delinear os tipos e conteúdos informacionais dos sujeitos.

\footnotetext{
2 Ainda há outros conceitos listados por Eagleton (1997, p. 15-16) que estão relacionados ao proselitismo informacional, mas de forma indireta. É possível listar os seguintes conceitos: Aquilo que confere certa posição a um sujeito; Formas de pensamento motivadas por interesses sociais; Pensamento de identidade; Ilusão socialmente necessária; A conjuntura de discurso e poder; $\mathrm{O}$ veículo pelo qual atores sociais conscientes entendem o seu mundo; Conjunto de crenças orientadas para a ação; A confusão entre realidade linguística e realidade fenomenal. Vale ressaltar que os conceitos listados nesta nota direcionam para outros conceitos do texto deliberando perspectivas substanciais para concretização do proselitismo informacional.
} 
O segundo conceito atesta o caráter pragmático da consciência humana de que a ideologia é "um pano de fundo" que regra a finalidade de produzir subsídios informacionais para dominação política (no sentido das tomadas de decisão que delineiam os rumos dos sujeitos). Esta prática ideológica é comumente pensada pela ampla maioria dos grupos de sujeitos que pensam a consolidação de suas finalidades, mas sem necessariamente primar pela ação apelativa de prejudicar outros grupos e sim pela consecução do debate e do respeito ao outro mesmo ponderando um ideário permanente de competitividade. A informação contemplada aqui é pragmática e o sujeito/grupo que mais se destaca é convencionalmente aquele produz as informações mais adequadas para as ações que envida. Esta contextualização ideológico-informacional é muito visível em ambientes profissionais e institucionais.

O terceiro conceito, embora derivado do segundo, se diferencia substancialmente em virtude de apresentar como ethos ideológico uma percepção teleológica aética. Neste caso, o que está em voga não é pura e simplesmente informação, mas contrainformação, já que os sujeitos não estão preocupados com a informação a ser produzida em si, mas sim como aquela informação promoverá a concretização do poder de um grupo de sujeitos independente dos mecanismos utilizados.

Em geral, a contrainformação aqui aludida apresenta dois sentidos contrapostos. O primeiro indica que a contrainformação é percebida como a capacidade de deturpar, dissimular e reificar para legitimar e dominar através da limitação do acesso à informação promovida pelos sujeitos dominantes (TRAVERSO; CROWDER-TARABORRELLI; PRADO, 2013). Já o segundo afirma que "a contra-informação é considerada como sendo a informação contrária à veiculada por um sistema” (FLUSSER, 1982, p.160).

Por um lado, a contrainformação atua como informação, mas representando de forma falseada e cínica da realidade. A contrainformação é por si só um produto informacional fabricado. Por um lado político-econômico e, por outro lado, ideológico da classe dominante. Bourdieu (2010, p. 12) adverte que:

A classe dominante é o lugar de uma luta pela hierarquia dos princípios de
hierarquização: as frações dominantes, cujo poder assenta no capital
econômico, têm em vista impor a legitimidade da sua dominação quer por
meio da própria produção simbólica, quer por intermédio dos ideólogos
conservadores os quais só verdadeiramente servem os interesses dos
dominantes por acréscimo, ameaçando sempre desviar em seu proveito o
poder de definição do mundo social que detêm por delegação.

A contrainformação como produto político-econômico se traduz nas formas de decisão e determinação do que pode e deve ser informado aos diversos setores da sociedade, definindo 
o uso adequado aos seus interesses dos meios diversificados de comunicação. Já a contrainformação como produto ideológico se constitui como estratégia dupla de ação: a primeira estratégia é referente aos postulados cognoscitivos do que deve ser atribuído como informação referente à satisfação das classes dominantes; a segunda é relativa às formas como os meios de comunicação formal (massa) traduzem seus interesses para a sociedade, perfazendo uma concepção padrão de que aquela informação é viável e promissora para a maioria.

Por outro lado, a contrainformação pode ser constituída como fenômeno de ação atrelado à desconstrução de uma determinada comunicação distorcida e construção de um novo processo informacional pautado em uma visão mais ampla da realidade envolvida. Mas é possível afirmar que a contrainformação só é efetiva quando é por natureza ou se torna um ato de resistência (DELEUZE, 1987) com vistas à transformação de uma determinada realidade.

O quarto conceito expressa um procedimento dos três primeiros, pois é uma maneira globalizante de dissimulação e dominação política, econômica e cultural que se sustenta a partir de uma concepção ideológico-informacional. É a capacidade que um grupo de sujeitos possui de convencer outros sujeitos através dos processos comunicacionais de massa, em especial, os meios de comunicação digital. Como afirma Andrade (2012) o poder da informação nos processos de globalização constrói uma opinião pública e modelos de representação social que legitimam o neoliberalismo. Nesse contexto, a cultura de massas induz que o poder da comunicação discursiva está dominado por uma ordem social que sustenta um modelo de produção que se desenvolve através do capital, a mercadoria e o mercado.

Diante desses quatro conceitos é pertinente argumentar sobre uma questão essencial que caracteriza o proselitismo informacional: a finalidade produzida pelos sujeitos da informação que pretendem dominar não é simplesmente aleatória e a-histórica como se fosse uma díade positivista de seres humanos malévolos dominando sujeitos inocentes, mas partem de contextos particulares, a saber:

a) a formação do inconsciente do sujeito - a ideologia impregna o eterno conflito entre o inconsciente coletivo e individual dos sujeitos tomando partidos para convencer outros sujeitos de que tal informação é a mais adequada, conforme suas conveniências culturais e históricas. Os psicólogos, os psicanalistas, e mais precisamente Freud, descobriram que, para além da consciência, há algo que é o inconsciente. Os sociólogos como Durkheim e, em um sentido mais moderno, 
Lévi-Strauss, descobriram que vivemos os fenômenos coletivos que guiam nossa conduta individual sem que tenhamos consciência deles. Haveria, pois, um "inconsciente de nossa conduta coletiva como há um inconsciente de nossa conduta individual.” (FOUCAULT, s.d).

b) consecução de mitos - nascem de faltas humanas relativas a ausência de uma “especialização biológica” da espécie (características inatas, aptidões naturais, equipamento biológico auto suficiente), que a lança em ter que se construir pelas suas próprias mãos, ao mesmo tempo em que necessita produzir um mundo próprio no qual poderá constituir-se, torna o sujeito dependente do espaço da cultura e da aprendizagem do que será, peça por peça, pela mão de um Outro (cultural, socializado). Essa dependência ontológica lança o ser humano na condição forçada de ter que se constituir pela via da transmissão da linguagem, a via do simbólico, e de sua consequente submissão à cultura e, nesse processo, desconhecendo os fundamentos dessa sua inscrição forçada no espaço da cultura e, portanto, ignorando igualmente como se funda como sujeito, o ser humano mantém uma relação de alienação com as condições de sua própria existência, em que, principalmente, desaparece como autor de seu próprio mundo e de si mesmo. (SOUSA FILHO, 2011, p. 10);

c) princípios imaginários do sujeito - toda ideologia se concretiza a partir de representações imaginárias da realidade. É neste ponto que a ideologia auxilia na produção de informações falseadas, pois nem toda representação ideológica constitui a informação mais premente para determinada realidade;

d) a ideologia como fator existencial da cultura do sujeito - a ideologia é uma forma de operação da cultura do sujeito, com vistas a manifestá-la e eternizá-la no seio de um sistema social. Este é o momento em que a informação alcança um nível de compreensão e apropriação social de forma utilitarista no sentido de estabelecer determinada cultura como ponto central de verdade e legitimidade social. A informação utilitarista pode estabelecer conflitos culturais como maneira de amadurecimento das culturas ou guerras culturais, com vistas à dominação de uma cultura sobre outra;

e) a ideia de ordem social - este talvez seja o ponto mais perigoso da ação ideológica, pois é o momento que os inconscientes (coletivo e individual), mitos, representações imaginárias e fundamentos culturais dos sujeitos se unem, com vistas a formulação de um viés único ou estratégico de ação que simbolize a 
verdade única e totalizadora da realidade. A ordem social é sustentada pelo poder político e comunicacional dominante que padroniza a informação como produto materializado e mercantil a ser consumido como referência cultural (cultura industrializada informação). Neste ponto, a informação se torna única, singular e representativa de uma cultura específica de vida e de uma conduta ideológica padrão de referência discursivo-social;

f) ideologia como formas de representação e função do cotidiano - representa os meios encontrados para lidar com questões do cotidiano. As formas ideológicas “são instrumentos pelos quais são conscientizados e enfrentados os problemas que preenchem (a) cotidianidade” (LUKÁCS, 1981, v. II, p.446) e que aparece não somente nos momentos de crise, mas de forma permanente no cotidiano. A informação parte dos aspectos cotidianos e têm em suas formas ideológicas fundamentos de representação e construção social de sentidos, atestando que formas ideológicas muitíssimo importantes como o costume, as convenções etc., nascem espontaneamente, e mesmo quando, no curso da diferenciação, se dão ideologias específicas nesta esfera, que às vezes podem adquirir um forte peso, a sua reprodução espontânea, por obra da sociedade, permanece o canal principal de sua existência, continuidade e transformação (LUKÁCS, 1981, v.II, p.482).

O proselitismo informacional é a concretização da singularidade sobre pluralidade; da individualidade sobre a coletividade; da uniculturalidade sobre a multiculturalidade; da informação como produto mercantil sobre a informação como produto humano; do discurso dissimulado sobre o discurso construído internacionalmente. O proselitismo informacional destrói a percepção de Maffesoli (1985) quando afirma que pluralismo não é uma vã questão: é, ao contrário, a chave da compreensão de toda organização social.

Em síntese, o proselitismo informacional tem um contexto ideológico quando um sujeito procura dissimular e deturpar para dominar outros sujeitos; tem um contexto linguístico quando busca no discurso estabelecer uma realidade fragmentada que dificulte a construção da informação de forma autônoma ou mesmo busque estabelecer um discurso como verdade única e totalizadora da realidade; tem ainda um contexto cultural quando favorece uma cultura de informação sobre as demais; tem um contexto político quando um pequeno grupo analisa e decide como os sujeitos devem obter acesso aos meios e instrumentos de produção da informação; tem, por fim, um contexto econômico quando disponibiliza o acesso aos meios e instrumentos de produção da informação, conforme classes 
sociais concebendo expressivas hierarquias em que a pluralidade é reduzida a singularidade daqueles que detêm o poder.

\section{Considerações finais}

A informação como fenômeno ideológico tem seu significado mais tendencioso, arbitrário e deturpador da realidade. Consiste na ideia de transformar a informação em mero indício de satisfação de intencionalidades, constituindo processos de práticas contrainformacionais.

No âmbito filosófico, a informação ideologizada é caracterizada por aspectos como interlocução unilateral (dependendo das condições de poder, a informação que mais se estabelece é aquela lançada por grupos dominantes ou a informação produzida por grupos dominantes é a que mais ecoa não possibilitando condições para resistência no escoamento de uma informação diferente) dominação (a informação tem o objetivo de estabelecer o poderio de um grupo sobre outro ou a aceitação da ideologia de um grupo perante grupos sociais), deturpação (a informação é produzida para distorcer critérios de veracidade ou desviar rumos de determinados fenômenos).

O proselitismo informacional se caracteriza, em especial, pela perspectiva de sujeitos ou grupos de sujeitos em tornar a informação fenômeno de distorção de fatos, intensificando a formação do inconsciente dos sujeitos, moldando crenças, cultura e imaginários dos sujeitos, a fim de estabelecer uma nova ordem social fundada na informação como fenômeno dado e definitivo.

Desse modo, o proselitismo informacional se situa em um conjunto de condutas e práticas sustentadas pelos seguintes fundamentos:

a) prática positivista - situa a informação como fenômeno balizado apenas pela experiência desconsiderando os processos de construção histórica, correlação de forças (humanas, cognitivas e psíquicas) e interações entre os sujeitos da informação;

b) prática utilitarista - a informação está fincada apenas nos resultados (consequências) relegando a um plano inferior as causas e procedimentos em que a informação é construída. O proselitismo informacional é utilitarista por não analisar a realidade de forma mais ampla e completa, mas envolver apenas um 
aspecto finalístico que favorece as intencionalidades do sujeito (ou grupos de sujeitos) que produz informação;

c) prática antiética - o proselitismo informacional é contrário à sustentação ética por pensar a prática contrainformacional no sentido de deturpar a realidade para satisfação de sujeitos em detrimento de outros. Neste ponto, a informação está quase sempre vinculada à correlação de forças em que o objetivo é estabelecer uma competição entre sujeitos ou grupos de sujeitos da informação vencendo aquele que popularizar de forma mais persuasiva às informações produzidas;

O proselitismo informacional é um fenômeno latente na sociedade contemporânea, em especial, em grandes corporações como as mídias de massa, bancos, empresas, indústrias, grupos políticos, entre outros, que desenvolvem práticas proselitistas de massificação informacional para convencer a sociedade dos rumos a serem seguidos. Logo, o proselitismo informacional resulta comumente na contrainformação que deturpa a realidade e foge a consagração de qualquer perspectiva de verdade.

Portanto, se toda informação é ideológica o que cabe aos sujeitos da informação não é ser a-ideológico, mas controlar racionalmente suas ideologias diante da realidade, de modo que a informação construída seja, minimamente, isenta de práticas positivistas, utilitaristas e antiéticas, além de ser pautada no pluralismo informacional e no respeito às diferenças entre os sujeitos.

\section{Referências}

ANDRADE, J. A. Globalización, ideología y cultura digital. Enl@ce: Revista Venezolana de Información, Tecnología y Conocimiento, v.9, n.3, p. 35-48, 2012. Disponível em: < http://www.redalyc.org/articulo.oa?id=82325415003>. Acesso em: 07 set. 2015.

BAKHTIN, M. Marxismo e filosofia da linguagem. 10. ed. São Paulo: Hucitec, 2002.

BOURDIEU, P. O poder simbólico. 13. ed. Rio de Janeiro: Bertrand Brasil, 2010.

CHAUI, M. O que é ideologia. São Paulo: Brasiliense, 1988.

DELEUZE, G. Ato de criação. Tradução: José Marcos Macedo, da Palestra de 1987. Folha de São Paulo, São Paulo 27 jun. 1999.

EAGLETON, T. Ideologia. São Paulo: UNESP, 1997.

FAIRCLOUGH, N. Discurso e mudança social. Brasília: Editora UNB, 2001. 
FLUSSER, V. “A contra-informação como ato cultural”. In: SILVA, Carlos Eduardo Lins (Org.). Comunicação, hegemonia e contra-informação. São Paulo: Cortez Intercom, 1982. p. 159-164.

FOUCAULT, M. “La inquietud del otro”. Cuaderno Transhumantes. Medellín, s.d.

LOGAN, R. K. Que é informação? A propagação da organização na biosfera, na simbolosfera, na tecnosfera e na econosfera. Rio de Janeiro: Contraponto, 2012.

LOWY, M. Ideologias e Ciência Social. 8. ed. São Paulo: Cortez, 1992.

LUKÁCS, G. "Il problema dell’ ideologia”, "Il lavoro come posizione teleológica” e "Il momento ideale nell'economia” In: Per l'ontologia dell'essere sociale. Roma, Editori Riuniti, 1981.

MAFFESOLI, M. L'ombre de Dionysos: contribution à une sociologie de l'orgie. Paris: Méridiens, Klincksieck et Cie, 1985 [edição brasileira: A sombra de Dionísio: contribuição a uma sociologia da orgia. Rio de Janeiro, Graal, 1985].

MANNHEIM, K. Ideologia e utopia. Rio de Janeiro: Zahar Editores, 1976.

MARX, K.; ENGELS, F. A ideologia alemã: teses sobre Feuerbach. São Paulo: Martins Fontes, 2001.

MÉSZAROS, I. O poder da ideologia. São Paulo: Boitempo, 2004.

SOUSA FILHO. A. de. Ideologia e transgressão. Revista Electrónica de Psicología Política (En Línea), v. 11, p. 207-224, 2012. Disponível em:

$<$ http://www.cchla.ufrn.br/alipiosousa/index_arquivos/ARTIGOS\%20ACADEMICOS/ARTI GOS_PDF/Ideologia\%20e\%20transgressao.pdf> Acesso em: 01 maio 2014.

THOMPSON, J. B. Ideologia e cultura moderna: teoria social crítica na era dos meios de comunicação de massa. 2 ed. Petrópolis: Vozes, 1998.

TRAVERSO, A.; CROWDER-TARABORRELLI, T.; PRADO, A. Anarchism and counterinformation in documentaries from Civil War Spain to post-2001 Argentina, Latin American Perspectives, v. 40, n. 1, p. 50-59, Jan. 2013. doi:10.1177/0094582X12446605. Disponível em: <http://lap.sagepub.com/content/40/1/50.full.pdf+html >. Acesso em: 07 jul. 2015. 